\title{
Effect of Refinery on Spearmint (Mentha spicata var. Viridis 1) Oil Quality
}

Salim RA ${ }^{1 *}$, Abu-Goukh ABA ${ }^{2}$, Khalid HES ${ }^{3}$ and El-Hassan GM ${ }^{4}$

${ }^{1}$ Food Industry Department, Industrial Research and Consultancy Centre, Ministry of Industry, Sudan

${ }^{2,4}$ Department of Hortiulture, Faculty of Agriculture, University of Khartoum, Sudan

${ }^{3}$ Medicinal and Aromatic Plants Institute, National Centre for Research, MOST, Sudan

\begin{abstract}
The experiment was to evaluate the effect of three levels of redistillation of spearmint oil on spearmint quality such as physicochemical properties of the oil. Spearmint (Mentha spicata var. Viridis) plants were raised from underground runners obtained from fully mature plants. Eighty milligrams of spearmint oil were distilled in $200 \mathrm{ml}$ of distilled water. Oil was extracted by water distillation according to the technique of British Pharmacopoeia. Physico-chemical properties including, relative density, optical rotation, refractive index, acid value and ester value were determined according to British Standards Institute. The process was repeated to give the first, second and third refined levels. Relative density, optical rotation and refractive index of spearmint oil significantly decreased with progress in the refining process. Acid values showed a decrease trend from 0.8475 in the crude oil to $0.5610,0.4210$ and 0.3740 in the first, second and third refined oils, respectively. Ester values significantly increased during the refining process from 11.22 in the crude oil to $12.01,13.09$ and 13.50 in the three levels of refining, respectively.
\end{abstract}

Keywords: Quality; Spearmint; Re-distillation; Physico-chemicals; Content; Components

\section{Introduction}

Mint plants and their products are widely used throughout the world for different purposes. They can be used with diet, food flavoring, folk medicines and confectioneries and other uses. The fresh and dried leaves are used as spice and flavoring agent $[1,2]$.

The mint oil consist of many oil components, the major component is the carvone constituent. Carvone content in fresh spearmint range between $42 \%$ and $60 \%[3,4]$. Other oil constituents include: limonene, carveol, sabinen, D-limonene, eucalyptol, Beta-myrcene and caryophyllene [5-7].

Many factors affect spearmint oil composition. Gapalakrishnan [8] mentioned that chemical changes in volatile compounds occur due to environmental conditions, such as light, oxygen, moisture, heat and storage period, resulting in the formation of artifacts or polymerization. Crude oil may require further processing prior to storage or transport, including filtering to remove solids impurities, drying to remove water and refining to reduce unwanted components or distillation. Oil production may contain resins and some impurities, so refining of the oil is needed to have pure oil to meet international standards. Therefore the degree and replication of refining process must be studied to avoid changes in pure quality oil, since redisitillation affects oil constituents and specifications.

The aim of this study was to evaluate the effect of three levels of redistillation of spearmint oil on composition and physico-chemical properties of the oil.

\section{Materials and Methods}

\section{Experimental site}

A field experiment was conducted at 'Halfaya' area, Khartoum North $\left(15^{\circ} 40^{\prime} \mathrm{N}, 32^{0} 22^{\prime} \mathrm{E}\right)$. The climate was a semi - arid, tropical, with seasonal annual rainfall of $120 \mathrm{~mm}$ during the period mainly between July to September. The mean maximum and minimum temperatures are as high as $47.5^{\circ} \mathrm{C}$ during summer and as low as $7.5^{\circ} \mathrm{C}$ during winter [9]. The soil was an alluvial type with high content of silt, slightly alkaline. Land preparation and cultural practices were carried out as recommended. The land was divided into 12 plots, 4.5 X $6 \mathrm{~m}$, each with
9 rows. At harvested the whole plot was covered with spearmint aerial herb (stem and leaves) due to spread of underground runners, which gives good aerial shoots at rhizome's nodes.

\section{Experimental material}

Spearmint (Mentha spicata var. Viridis) plants were raised from underground runners (rhizome-like rootstock). They were obtained from fully mature plants grown in spearmint growing area at 'Halfaya', Khartoum North, Sudan. The underground and surface runners were transplanted into new well prepared flat beds at $30 \times 30 \mathrm{~cm}$ spacing. Pre-transplanting irrigation was applied followed by the first irrigation immediately after transplanting. Irrigation was carried out every 7.

\section{Experimental design}

The experiment was laid out in a randomized complete design with three replications. The treatments were: (i) crude oil (before redistillation), (ii) first redistillation (first refining), (iii) second redistillation (second refining) and (iv) third redistillation (third refining).

\section{Harvesting and herb preparation}

Sample of herb, about two kilograms each, were harvested from well established 60 days plants. The aerial parts of the plants (main aerial stem, branches and leaves) were cut about $5 \mathrm{~cm}$ above the ground level. Foreign materials and weeds were removed immediately from the harvested material. The samples were distributed into three groups, replicated four times and were transferred in black polyethylene bags to the laboratory for further investigations.

*Corresonding author: Rasheed Ahmed Salim, Food Industry Department Industrial Research and Consultancy Centre, Ministry of Industry, Sudan, E-mail: rasheedahmedsalim@hotmail.com

Received May 04, 2015; Accepted July 03, 2015; Published July 10, 2015

Citation: Salim RA, Abu-Goukh ABA, Khalid HES, El-Hassan GM (2015) Effect of Refinery on Spearmint (Mentha spicata var. Viridis I) Oil Quality. J Food Process Technol 6: 481. doi:10.4172/2157-7110.1000481

Copyright: $\odot 2015$ Salim RA, et al. This is an open-access article distributed unde the terms of the Creative Commons Attribution License, which permits unrestricted use, distribution, and reproduction in any medium, provided the original author and source are credited. 


\section{Herb preparation}

Foreign materials and weeds were removed immediately from the harvested spearmint, and the spearmint samples were transferred in black polyethylene bags to the laboratory for further investigations.

\section{Oil extraction and determination}

Oil was extracted by water distillation and determined according to the technique of British Pharmacopoeia [10].

\section{Refining process}

Eighty milligrams of spearmint oil were added to $500 \mathrm{ml}$ round bottom flask. $200 \mathrm{ml}$ of distilled water was added to the flask. The mixture in the flask was placed in a heating mantle. A condenser was supplied to the flask. The round bottom flask with its contents was allowed to boil till all volatile oil evaporated form the flask, till the volume of the oil in the receiver remained constant for half an hour. The condensate was received into separating funnel. The process was repeated to give first refining, second refining and third refining.

\section{Oil preparation}

The oil was prepared according to British Standard Institution [11].

\section{Determination of physical properties}

Relative density: The relative density of spearmint oil was measured using Adam Equipment AEP - $250 \mathrm{G}$ - Electronic Balance type AEP Series, provided with a density determination kit (Adam Equipment Co. Ltd - Miltton Keynes 2004, UK) according to British Standards Institute [11].

Optical rotation: Optical rotation of spearmint oil was measured using an Automatic Digital Polarimeter (P 300301 RS AKRUSS. OBTRONIC-Germany) optical rotation instrument according to British Standards Institute [11].

Refractive index: The refractive index of the oil was determined by Abbe refractometer No. 918095 (Bellingham and Stanley Ltd, London, England) according to British Standards Institute [11].

\section{Determination of chemical properties}

Chemical properties; acid value and ester value; of spearmint oil were determined according to British Standard Institute [11].

\section{Statistical analysis}

Analyses of variance, followed by Duncan multiple range test with significance level $\mathrm{p} \leq 0.05$ were performed on the data [12].

\section{Results and Discussion}

\section{Effect on physical properties}

The relative density of spearmint decreased with progress in the refining process (Figure 1). It decreased from 0.913 in the crude oil to $0.912,0.911$ and 0.894 in the first, second and third refined oils respectively. Significant differences were found between the crude and the first refined oil and between the second and third refined oils, but no significant difference was noticed between the first and second refined oils. Spearmint relative density at $20 / 20^{\circ} \mathrm{C}$ is $0.920-0.937$ according to ISO 3033: $1988[13,14]$. Americam spearmint specification is in the range 0.917 to 0.934 [15]. The relative density of the oil is a function of different relative densities of its components, some are lighter and others are heavier. It was reported earlier that environmental conditions, including temperature, moisture, oxygen and light might lead to resinification of essential oil and changes in oil composition $[15,16]$. During the refining process and due to the high temperature, some oil components might evaporate, which might explain the decrease in relative density of the more refined spearmint oil.

Optical rotation was significantly higher in the crude oil (-46.65), followed by the first $(-46.620)$, second $(-46.595)$ and third (-46.585) refined oils (Figure 2). No significant difference was observed between the second and third refined oils. All the optical rotation values were within the range of -40 to -60 at $20^{\circ} \mathrm{C}$ mentioned by Furia and Bellanca [17] and within the range -45 to -60 optical rotation at $20^{\circ} \mathrm{C}$ recommended by ISO 3033:1988 [13]. Environmental conditions significantly affect mint oil content, composition and quality $[2,18]$. Due to the refining process, some of the oil components might be removed. Since optical rotation is a function of optical rotations of the different components of the oil, the decrease in optical rotation could be due to changes in the composition of the oil after refining, which affect polarization of light passing through the oil and consequently the optical rotation.

The effect of temperature, water, oxygen during the redistillation process might lead to isomerization, oxidation, resinification and decomposition of the volatile oil constituents $[2,3,18]$. The decrease in optical rotation in the refined oil could be due to changes in composition

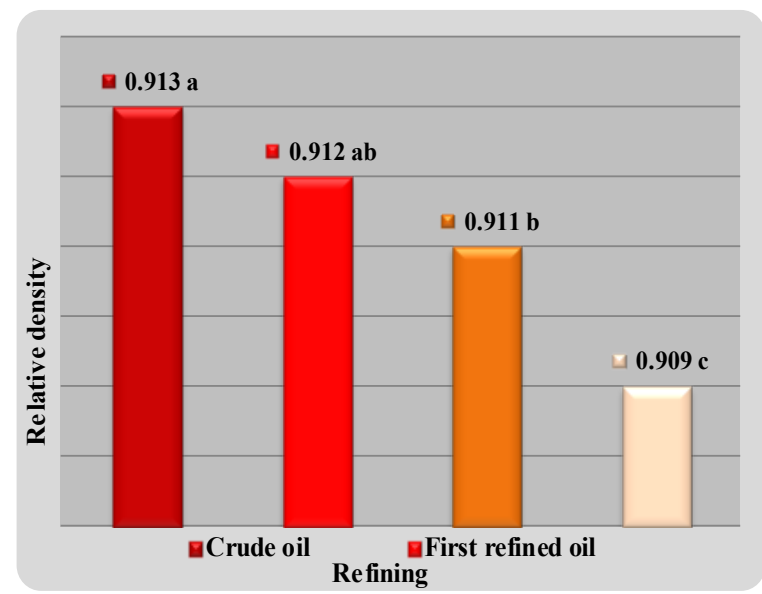

Figure 1: Relative Density of crude, firstrefined, second refined and third refined spearmint oil during the re-distillation process.

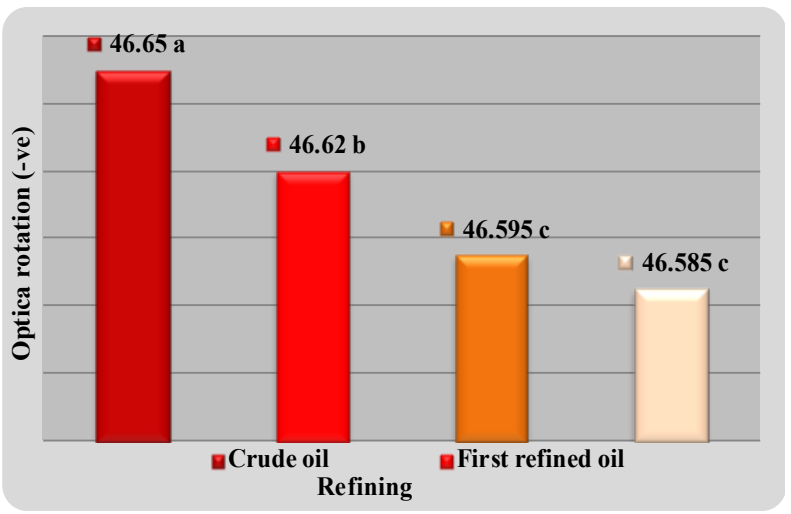

Figure 2: Optical Rotation of crude firstrefined, second refined and third refined spearmint oil during the re-distillation process. 
of the oil or the rate of evaporation of the different components of the oil.

Refractive index was highest in the crude oil (1.4815), followed by the first refining (1.4810), second refining (1.4782) and least in the third refining oil (1.4755) (Figure 3). There was no significant difference between the crude oil and the first refined oil, but there were significant differences between the first and the second refined oils and the second and third refined oils. The refractive indices of the different refined oils were close to the range of 1.484 to 1.491 reported for spearmint by Suburg and Kospel [14] and greater than that of Italian spearmint (1.4691) and the Indian spearmint (1.468) reported by Guenther [16]. Since optical rotation is a function of optical rotation of the different components, the decrease in optical rotation could be due to the effect of temperature, water, oxygen during the redistillation process, which might lead to isomerization, oxidation, resinification, recomposition and decomposition of the volatile oil constituents $[2,3,18]$. Moreover, essential oil constituents have their own specific functional groups that determine the degree of light incidence and refraction of light in the oil and consequently the refractive index might be changed.

\section{Effect on chemical properties}

The acid values showed a decrease trend from 0.8475 in the crude oil to $0.5610,0.4210$ and 0.3740 in the first, second and third refined oils, respectively (Figure 4). Significant differences were found between the crude and other stages of refining and between the first, second and third refined oils, but no significant difference was observed between the second and third refined oils.

Ester values significantly increased during the refining process from 11.22 in the crude oil to $12.01,13.09$ and 13.50 in the first, second and third refined oils, respectively (Figure 5). These changes in acid value and ester values were most probable due to chemical changes of the essential oil, which lead to changes in oil constituents and composition. Acid value and ester values were reported to differ according to geographic and environmental conditions [16]. The high temperature during the redistillation process might lead to isomerization, oxidation, resinification, recomposition and decomposition of the volatile oil constituents $[2,3,17]$. Moreover, the heating during redistillation promotes esterification of the functional groups between alcohols and acid radicals in the oil and consequently reduces the acid radicals by forming ester bonds in the presence of the alkali $(\mathrm{KOH})$ in the test (BSI, 1976). Simonsen $[18,19]$ postulated that oxidation of carvone can lead to a variety of products in the presence of analkali, such as $\mathrm{Ba}(\mathrm{OH})_{2}$. Carvone is oxidised by air or oxygen to give the diketone, and with hydrogen peroxide the epoxide is formed and carvone may be cleaved using ozone followed by steam giving dilactone. These changes in the functional groups were reflected in a decrease in acid values and an increase in ester values during the first and second steps of refining process. During the third refining process, it seems that most of that the acid radical were transformed to ester radicals and a stable ester formula was formed, and the acid and ester values remained constant or changed very little with no significant differences. This agrees with the British Standard 2073:1976 concept of acid and ester value [13].

\section{Conclusion}

The relative density, optical rotation and refractive index of spearmint oil significantly decreased with progress in the refining process. Acid values showed a decreased trend and ester values increased with advancement of refining.

\section{Acknowlgement}

I wish to express my thanks to the staff in the Department of Horticulture (Faculty of Agric., U. of K., Sudan), Medicinal and Aromatic Plants Institute (NCR, Sudan), Department of Food Research Industries at (IRCC, Sudan), Mr.

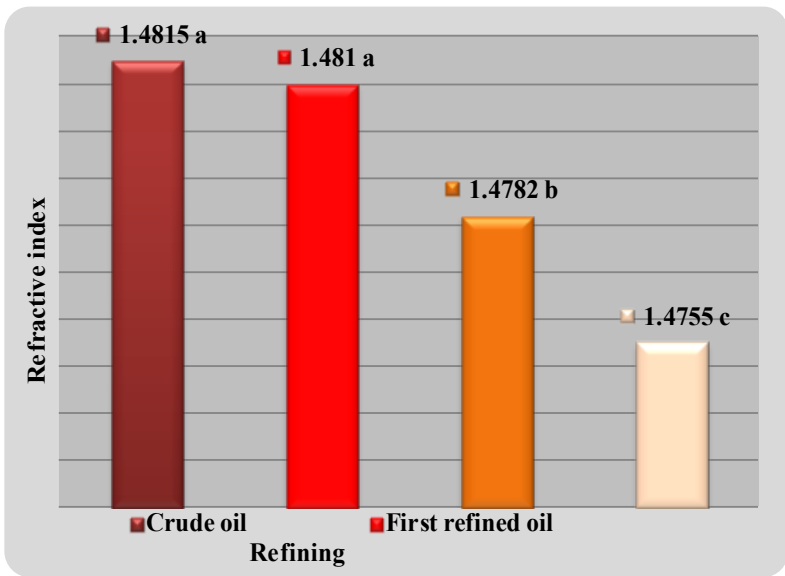

Figure 3: Refractive Index of crude, first refined, second refined and third refined spearmint oil during the re-distillation process.

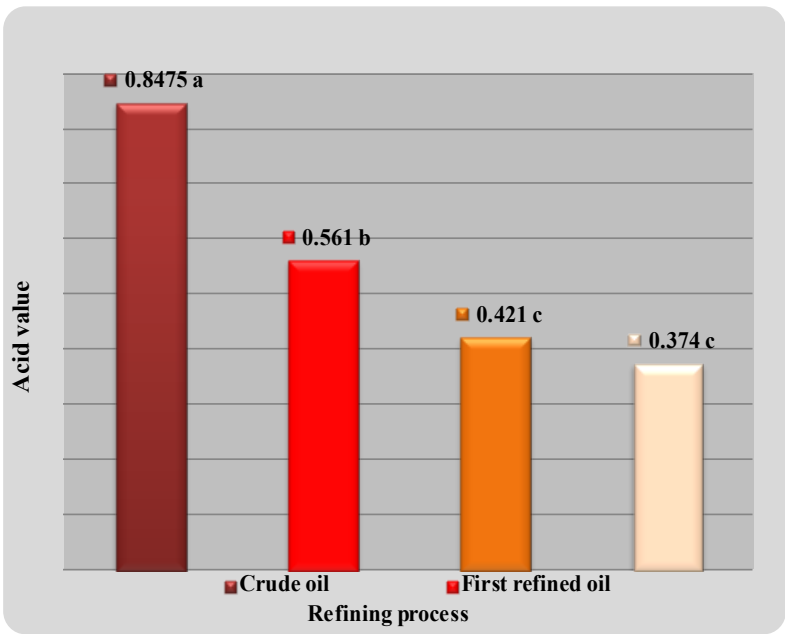

Figure 4: Acid Value of crude, first refined, second refined and third refined spearmint oil during the re-distillation process.

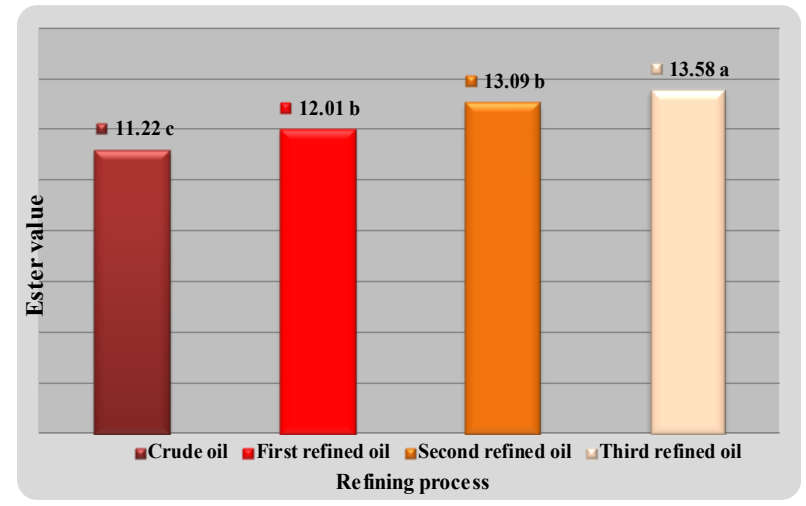

Figure 5: Ester Value of crude first refined, second refined and third refined spearmint oil during the re-distillation process. 
Citation: Salim RA, Abu-Goukh ABA, Khalid HES, El-Hassan GM (2015) Effect of Refinery on Spearmint (Mentha spicata var. Viridis I) Oil Quality. J Food Process Technol 6: 481. doi:10.4172/2157-7110.1000481

Mohammed Damona in Pharmaceutical Industries (IRCC) for their generous help in conducting extraction and chemical tests, Central Laboratory (MOST) with specia thanks to Ms. Missa, GC-MS department for their generous technical assistance and friendly attitudes and cooperation during the course of this study. My thanks are to IRCC for financing this research.

\section{References}

1. Murray MJ, Faas W, Marble P, (1972) Chemical composition of Mentha arvensis var. Piperascens and four hybrids with Menthacrispa harvested at different times in India and Michigan. Crop Science 12: 742-745.

2. Aflatuni $A$ (2005) The yield and essential oil content of mint (Mentha ssp.) in Northern Ostrobothnia. Faculty of Science, Department of biology, University of Oulu, Finland.

3. Hussein FTG (1987) The medicinal plants: Cultivation and composition. Kymfeto Press Company, Sudan Street, Jeza, Cairo, Egypt.

4. Haykal ME, Omer AA (1993)Medicinal and aromatic plants. Dar El Maaref Press, Alexandria, Egypt.

5. Alonso WR, Rajaonarivony JM, Gershenzon J, Croteau R (1992) Purification of $4 S$-limonene synthase, a monoterpenecyclase from the glandular trichomes of peppermint (Menthapiperita) and spearmint (M. spicata). Journal of Biological Chemistry 267: 7582-7587.

6. Colby SM, Alonso WR, Katahira E, Mc Garvey DJ, Croteau R (1993) 4S-Limonene synthase from the oil glands of spearmint (Menthaspicata): cDNA isolation, characterization, and bacterial expression of the catalytically active monoterpenecyclase. Journal of Bilogical Chemistry 268: 23016-23024.

7. Ashurt PR (1995) Food Flavorings. Blackie Academic and professional, 2-6 Boundary Row, London, UK.

8. Gopalakrishnan N (1994) Studies on the storage quality of carbon dioxideextracted cardamom and clove bud oils. Journal of Agricultural and Food Chemistry 42: 796-798.
9. SMAR (2010) The Climatological Normals (1981-2010). Sudan meterological authority records (SMAR), Ministry of Environment, Forestry and Physical Development, Sudan.

10. GMC (1968) British Pharmacopeia. General Medicinal Council (GMC). The Pharmaceutical Press, UK.

11. BSI (1976) Methods of Test for Essential Oils. British Standard Institution (BSI), 2 Park Street London, UK.

12. Gomez KA, Gomez AA (1984) Statistical Procedures for Agricultural Research (2ndedn). An International Rice Research Book.A Wailey-Intersclence publication.

13. ISO 3033 (1988) Oil of Spearmint (Menthaspicata Linnaeus). International Organization for Standardization (ISO).

14. Surburg H, Köpsel M (1987)New naturally occurring sesquiterpenes from scotch spearmint oil (Menthacardiaca Ger.). Journal of Flavor and Fragrance 4: $143-147$

15. Guenther E (1975) The Essential Oils. Robert E, Krieger Publishing Company, Huntington, New York, USA.

16. Abu-Zeid AN (1992) Aromatic plants and their agricultural and pharmaceutical products. (1stedn). Al Dar Al Arabia for Printing and Distribution. Cairo, Egypt.

17. Furia ET, Bellanca N (1975) Handbook of Flavoring Ingreients. CRC press, Icranwood Parkway - Cleveland, Ohio, USA.

18. Farooqi AHA, Samgwan NS, Sangwan RS (1999) Effect of different photoperiodic regimes on growth, flowering and essential oil in Mentha species. In: Plant Growth Regulation 29: 181-187.

19. Simonsen JL, Ross WCJ (1957)The Terpenes. The Triterpenes and thei derivative s-hydroxy acids, hydroxy lactones, hydroxyaldehydoa. Cambridge University Press, USA 